\title{
Empenhamento organizacional dos enfermeiros num hospital de Portugal: análise do impacto da reestruturação organizacional
}

\section{Nurses' organizational commitment in a hospital in Portugal: analysis of the impact of organizational restructuring}

Compromiso organizacional de los enfermeros en un hospital en Portugal: impacto de la reestructuración organizacional

\author{
Maria Manuela Frederico Ferreira ${ }^{I}$
}

\begin{abstract}
RESUMO: A reestruturação organizacional tem, muitas vezes, impacto no comportamento dos colaboradores. O estudo é, sobretudo, de natureza exploratória, com abordagem predominantemente quantitativa, descritiva e correlacional, tendo como objetivos avaliar o impacto do processo de reestruturação nos níveis de empenhamento organizacional dos enfermeiros; avaliar se existe diferença entre esses níveis antes e após o processo de reestruturação; fornecer algumas recomendações e / ou sugestões, com o intuito de reforçar o empenhamento organizacional. O instrumento de coleta de dados utilizado foi o questionário, aplicado em 2011. A amostra é constituída por 158 enfermeiros que vivenciaram o processo de reestruturação organizacional e, assim, emitem opinião sobre alterações nas relações com a instituição. A informação fornecida sobre as mudanças no hospital e sobre o modo como essas mudanças poderiam afetar foi considerada insuficiente por uma percentagem considerável dos participantes. É notória a diminuição das relações afetivas e normativas dos enfermeiros com a organização. Palavras-Chave: Lealdade; enfermeiras; reestruturação hospitalar; empenhamento organizacional.
\end{abstract}

\begin{abstract}
Organizational restructuring often has impact on collaborators' behavior. This exploratory, descriptive, correlational study examined the impact of restructuring processes on levels of organizational commitment among nurses, to assess whether levels differ before and after the restructuring process, and provide recommendations and/or suggestions for enhancing organizational commitment. Data were collected by questionnaire in 2011 from the sample of 158 nurses who experienced the process of organizational restructuring and thus can give opinions about changes in relations with the institution. The information provided on changes in the hospital and the effect these changes might have was considered insufficient by a considerable proportion of the participants. These findings highlight the nurses' diminishing normative and affective relations with the organization.

Keywords: Loyalty; nurses; hospital restructuring; organizational commitment.
\end{abstract}

RESUMEN: La reestructuración organizacional tiene, frecuentemente, impacto en el comportamiento de los empleados. E estudio es de naturaleza principalmente exploratoria, descriptiva y correlacional y tiene como objetivos evaluar el impacto del proceso de reestructuración en los niveles de compromiso organizacional de los enfermeros; evaluar si hay diferencias entre los niveles de compromiso organizacional antes y después del proceso de reestructuración; proporcionar algunas recomendaciones y/o sugerencias, con el objetivo de potenciar el compromiso organizacional. El instrumento de recolección de datos utilizado fue el cuestionario aplicado en 2011. La muestra constó de 158 enfermeros que experimentaron el proceso de reestructuración organizacional y, de esa forma, emiten opinión sobre los cambios en las relaciones con la institución. La información proporcionada sobre los cambios en el hospital, y sobre la forma en que estos cambios podrían afectar, se considera insuficiente para una proporción considerable de los participantes. Estos resultados ponen de relieve la disminución de las relaciones afectivas y normativas de los enfermeros con la organización.

Palabras Clave: Lealtad; enfermeros; reestructuración hospitalaria; compromiso organizacional.

\section{INTRODUÇÃO}

Fruto do estudo de comportamento organizacional, sabe-se que o comportamento humano nas organizações é influenciado por características situacionais e por características do indivíduo. Dessa forma, podem ser criados fatores que motivem ou induzam o indivíduo a adotar determinado comportamento ou atitude. Ou seja, têm-se definido fatores que levam o indivíduo a agir de uma forma particular ${ }^{1}$, conciliando os interesses pessoais com os da organização.

A mudança, em geral, e reestruturação organizacional, hoje vivida em serviços de saúde de diferentes países - muitas vezes com políticas impostas -, determinam consequências nos serviços de enfermagem² ${ }^{2}$.

Os enfermeiros representam uma parcela significativa dos recursos humanos alocados nas instituições de

'Doutora em Ciências Empresariais. Pós-Doutora em Ciências Empresariais. Professora Coordenadora da Escola Superior de Enfermagem de Coimbra, Conselho para a Qualidade e Avaliação. Coimbra, Portugal. E-mail: mfrederico@esenfc.pt. 
saúde, principalmente, nas instituições hospitalares ${ }^{3}$ e são fortemente visados nas reestruturações organizacionais.

Foram objetivos desta investigação avaliar o impacto do processo de reestruturação nos níveis de empenhamento organizacional dos enfermeiros; avaliar se existe diferença entre esses níveis antes e após o processo de reestruturação; fornecer algumas recomendações e/ou sugestões, com o intuito de reforçar o empenhamento organizacional.

\section{RevisÃo DE Literatura}

O empenhamento organizacional, como o laço psicológico que caracteriza a ligação dos indivíduos à organização, parece ser um bom indicador da conciliação desses interesses, pois prevê as intenções comportamentais dos colaboradores ${ }^{4}$. $\mathrm{O}$ interesse manifestado por este construto baseia-se no pressuposto da existência de associação a variáveis consideradas importantes para o aumento da eficácia e da produtividade organizacional ${ }^{5}$. Na mesma linha ${ }^{6}$, o empenhamento organizacional, em termos teóricos, influencia vários comportamentos importantes para o bom funcionamento das organizações, tais como a intenção dos colaboradores em permanecer na organização, de realizarem um esforço em seu benefício e de terem um desempenho elevado. Também deve ser considerada a relação interpessoal, pois os liderados apontam que o respeito e confiança de seus líderes é um fator primordial nas relações?

As componentes de empenhamento organizacional, nomeadamente a afetiva (estabelecida num vínculo emocional à organização) e a componente normativa (baseada em reciprocidade, reflete um sentimento de obrigação em continuar na organização) não devem ser vistas como tipos de empenhamento únicos que caracterizam o empenhamento de um colaborador. Antes, devem considerar que os colaboradores podem experimentar cada um destes estados psicológicos em diferentes graus.

Pode-se afirmar que as organizações têm interesse em promover os laços afetivo e normativo dos seus colaboradores, mas para que isso ocorra, é necessário que as organizações conheçam o nível de empenhamento organizacional dos seus colaboradores e variáveis que o podem determinar ${ }^{3}$.

As políticas organizacionais que colocam ênfase na rentabilização e racionalização, no desenvolvimento e mérito dos profissionais, e na atribuição de incentivos distinguem os modelos de gestão hospitalar, mas poderão, simultaneamente, ter implicações no empenhamento dos profissionais.

A enfermagem constitui um grupo profissional fortemente visado, com as alterações e reestruturações ocorridas nas instituições de saúde. Os estudos cujo objeto de análise é centrado nos efeitos das reformas no setor da saúde, sobre a profissão de enfermagem, abordam um conjunto diverso de questões essencialmente estruturadas em torno dos temas relacionados com as mudanças na cultura e nos papéis profissionais ${ }^{8,9}$.

As consequências das reestruturações e os desafios colocados tanto nas práticas clínicas quanto no âmbito da gestão e no volume de trabalho dos enfermeiros são notórios. No caso da gestão, verifica-se alguma diminuição do poder de intervenção dos enfermeiros no funcionamento administrativo dos hospitais. No que respeita ao volume de trabalho, o aumento do número de tarefas poderá ser traduzirdo numa alteração dos papéis profissionais e na delegação de tarefas menos especializadas a outros profissionais detentores de qualificações inferiores.

Estas alterações provocam mudanças na própria organização do trabalho, que poderão se traduzir numa presença simultânea dos modelos fordista e pós-fordista de organização do trabalho. Efetivamente, algumas técnicas da nova gestão pública são coincidentes com as práticas fordistas, como o aumento da rotinização, a diminuição do nível de competências exigidas e do aumento do controle da gestão sobre o processo de trabalho, ${ }^{9,10}$, enquanto outras se situam na perspectiva pós-fordista, como a flexibilidade, a polivalência e a mobilidade? .

\section{Metodologia}

Este projeto é, sobretudo, de natureza exploratória, tendo como objetivos: avaliar o impacto do processo de reestruturação nos níveis de empenhamento organizacional dos enfermeiros; avaliar se existe diferença entre os níveis de empenhamento organizacional antes e após o processo de reestruturação; fornecer algumas recomendações e/ou sugestões, com o intuito de reforçar o empenhamento organizacional. A abordagem é predominantemente quantitativa, descritiva e correlacional.

$O$ instrumento de coleta de dados utilizado foi o questionário. É um documento de quatro páginas, composto por três grupos de questões. $O$ primeiro grupo, com questões abertas e fechadas, refere-se à informação oferecida no processo de mudança e às alterações nas relações com a instituição. Neste grupo, relativamente à opção de resposta escolhida, em cada questão fechada, pediu-se a respectiva justificativa. Na introdução ao questionário, para além da apresentação e enquadramento do estudo, foi apresentado o sentido atribuído a 'mudanças no hospital'. Citando: Quando referimos 'mudanças no hospital' reportamos à transição de hospital SPA (Setor Público Administrativo), para hospital EPE (Entidade Pública Empresarial). O segundo grupo, com 40 afirmações, utiliza uma escala de concordância tipo Likert, (de 1 a 5, em que 1 corresponde a ...discordo em absoluto..., 2 a ...discordo em 
parte..., 3 a ...não tenho opinião..., 4 a ...concordo em parte.. e 5 a ...concordo em absoluto..., relacionada ao empenhamento: afetivo, normativo e instrumental e à percepção do suporte organizacional. $O$ terceiro grupo apresenta questões referentes aos dados biográficos.

A variável empenhamento organizacional baseia-se na escala organizational commitment ${ }^{11,12}$ validado e já aplicado em profissionais de saúde em Portugal ${ }^{13}$.

Após os procedimentos formais de apresentação do projeto e do questionário à comissão de ética (Parecer $n^{0}$ 40-09/2011) e autorização pela direção do hospital, o questionário foi distribuído, de forma individualizada, a todos os enfermeiros, em envelopes, a fim de, após preenchimento, poder ser fechado. $\mathrm{O}$ processo de distribuição e recolha ocorreu em 2011.

A unidade de análise são os enfermeiros, contudo foi condição necessária ao estudo que os enfermeiros exercessem funções numa instituição hospitalar em que tivesse decorrido um processo de reestruturação em seu modelo de gestão. Assim, os enfermeiros que constituem a amostra exercem funções em hospitais que sofreram reestruturação do seu modelo de gestão em 2005. A participação foi voluntária e consentida e as questões de anonimato e confidencialidade foram asseguradas, conforme os princípios éticos da pesquisa. O questionário foi entregue em envelope individualizado, para poder ser fechado após preenchimento e depositado, pelo próprio respondente, em caixa fechada com ranhura, não havendo qualquer identificação de quem respondeu.

Os dados foram quantitativos e processados em computador, por meio do programa estatístico Statiscal Package for the Social Sciences (SPSS), versão 19 para Windows, tendo realizado estatísticas descritivas. Para as respostas abertas, utilizou-se a metodologia de análise de conteúdo.

Foram entregues 723 questionários; destes, 53 foram devolvidos em branco, ou seja, não preenchidos, quatro foram preenchidos de forma incompleta e 502 não foram devolvidos. Foram devolvidos convenientemente preenchidos 164 , sendo este o número de questionários válidos para o estudo. Este número traduz uma taxa de resposta de $22,7 \%$.

Do total de questionários válidos, seis enfermeiros referiram que não trabalhavam no hospital antes de ser EPE. Assim, as suas respostas não foram incluídas nos dados do primeiro grupo de questões, pois este reporta-se ao processo de mudança e à opinião sobre alterações nas relações com a instituição.

A análise que se apresenta considerou o estudo de 2011 e algumas comparações com os resultados obtidos de estudo realizado em $2002^{13}$, em que se utilizou o mesmo instrumento de medida empregado em 2011.

\section{Resultados e Discussão}

Em 2011, a amostra apresenta um predomínio $135(82,4 \%)$ do sexo feminino. $\bigcirc$ grupo etário mais expressivo é dos 30-39 anos 79(48,2\%). A categoria profissional mais representada é de enfermeiro nível I (nível inicial da carreira de enfermagem) 114(69,7\%); segue-se a categoria de enfermeiro graduado $30(18,3 \%)$ e de enfermeiro especialista $27(16,4 \%)$. Ainda, 54(33,1\%) enfermeiros, que responderam ao questionário, trabalham na organização há menos de 10 anos.

\section{Informações sobre as mudanças}

A informação fornecida sobre as mudanças no hospital, antes que elas ocorressem, e sobre o modo como o poderiam/iriam afetar, foi considerada insuficiente por 75(47,5\%) participantes, conforme mostra a Tabela 1.

Os processos comunicacionais e a informação são estratégias necessárias ao líder, os quais permitem o entendimento das informações, sendo um meio para a interação entre as pessoas e troca de opiniões. $\mathrm{O}$ vínculo pode ser obtido pela valorização e compreensão de pontos de vista, já que cada um dos sujeitos vivencia essa situação conforme a sua própria experiência, estabelecendo intercâmbio de perspectivas subjetivas?

Foram apresentadas 53 justificativas, sendo que 48 delas são de enfermeiros que consideraram a infor-

TABELA 1: Opiniões de enfermeiros acerca da informação fornecida sobre a reestruturação organizacional. Portugal, 2011. (N=158)

\begin{tabular}{|c|c|c|c|c|c|c|c|c|}
\hline \multirow{2}{*}{ Opiniões } & \multicolumn{2}{|c|}{$\begin{array}{l}\text { Mais do que } \\
\text { suficiente }\end{array}$} & \multicolumn{2}{|c|}{ Suficiente } & \multicolumn{2}{|c|}{ Insuficiente } & \multicolumn{2}{|c|}{ NR } \\
\hline & & $\%$ & $f$ & $\%$ & $f$ & $\%$ & $f$ & $\%$ \\
\hline $\begin{array}{l}\text { Antes das 'mudanças no hospital' a informa- } \\
\text { ção fornecida sobre essas mudanças e sobre } \\
\text { o modo como o poderiam/iriam afetar, foi }\end{array}$ & 2 & 1,3 & 62 & 39,2 & 75 & 47,5 & 19 & 12,0 \\
\hline $\begin{array}{l}\text { A informação que recebeu sobre o futuro } \\
\text { estatuto/regulamento do seu serviço/depar- } \\
\text { tamento / equipe de trabalho foi }\end{array}$ & 5 & 3,2 & 66 & 41,8 & 67 & 42,4 & 20 & 12,7 \\
\hline
\end{tabular}

$N R=$ não respondido 
mação insuficiente. Essas justificativas situaram-se na ausência de informação, na referência da necessidade de entender a mudança; de ser integrado como elemento participativo no processo; de haver motivação para a mudança, como se ilustra pelos seguintes excertos:

\section{Não houve informação. (E7)}

A organização deveria ter informado quais as alterações que iam acontecer. (E35)

Não foi fornecida qualquer tipo de informação. O que muda? Que consequências directas têm para a pessoal e serviço? (E74)

Apenas, informação que nos permitisse entender em que consistia essa mudança. (E91)

Continuo sem saber muito bem as alterações decorrentes desta alteração, seria importante uma sessão de esclarecimento aos profissionais [...]. (E13)

[...] informação que nos permitisse entender em que consistia essa mudança. [...]. (E123)

A informação fornecida directamente da organização foi nula. O conhecimento da situação foi apenas através da comunicação social. (E19)

Apesar da justificativa ser pedida apenas no caso de considerar a informação insuficiente, houve cinco enfermeiros que consideraram a informação suficiente e, ainda assim, apresentaram justificativa. Os excertos permitem conhecer o sentido dessas justificações:

Existiu um debate em sala onde foram explicadas as modificações. (E4)

Houve reunião prévia com enfermeiros. (E27)

Lembro-me que tivemos uma reunião com o Enfermeiro Director, em que este explicou muito bem: ou assinávamos pela EPE ou saíamos do hospital (na altura era contratada a termo certo). (E56)

Por ser essencialmente decisão política, foi resolvido praticamente sem discussão pública e de 'um dia para o outro'. (E78)

Não me apercebi da mudança nenhuma. Na verdade, também não me interessa como é que deveria ser. Acho que os doentes têm os cuidados necessários, independentemente de quem gere. (E141)

A informação que relatam ter recebido sobre o futuro estatuto/ regulamento do seu serviço / departamento / equipe de trabalho foi considerada insuficiente por $67(42,4 \%)$ participantes, mas foi considerada suficiente por 66(41,8\%), segundo a Tabela 1.

No questionário, pediu-se que a resposta fosse justificada e, no caso de considerar a informação insuficiente, referir que informação deveria ter recebido. Foram apresentadas 36 justificativas. Essas justificativas situaram-se na necessidade de informação para se adaptar à mudança, para diminuir a incerteza, para conhecer as implicações para os colaboradores, como se ilustra pelos seguintes segmentos de texto:

Não houve qualquer informação. Houve mudanças nos contratos - mudanças nas equipas pelo acréscimo de horas. As práticas mantiveram-se. (E20)

Só estando bem esclarecidas as informações, e sermos detentores da informação nos podemos adaptar à mudança. Têm que nos empoderar de conhecimento de capacidades, têm que nos motivar para melhor desempenharmos as nossas funções. (E47)

Não me apercebi de mudanças na equipa de trabalho relacionadas com as mudanças no hospital. (E90)

As mudanças que se verificaram partiram da equipa de trabalho no sentido de melhorar os cuidados prestados e dar resposta ao acréscimo de utentes atendidos diariamente neste serviço. (E105)

Existe uma grande incerteza no local de trabalho onde exerço, não se sabendo qual o rumo que irá tomar o serviço no que diz respeito a especialidades médicas. Essa informação não foi fornecida. (E74)

O que muda? Vantagens/desvantagens? (E123)

Funcionalmente a nível dos serviços não senti alterações, contudo foi escassa a informação sobre o futuro estatuto. O sentimento era: 'esperar para ver!' fui informada de que iria passar a trabalhar 40 horas semanais, receber uma remuneração equivalente a esse aumento da carga horária. (E39)

Os regulamentos são obscuros ou não existem. As mudanças não melhoraram os procedimentos/normas/ regulamentos parcos, que existiram. (E53)

Qual estatuto? Os regulamentos são os mesmos. $\mathrm{Na}$ prática não houve mudança [...]. (E91)

[...] Pelo menos deveriam ser publicadas em B.I. as alterações. (E19)

Informação acerca das implicações prejudiciais aos trabalhadores. (E66)

Continuei a desempenhar as mesmas funções [... ]. (E25)

As modificações a nível jurídico, administrativas e em que medida essas alterações se relacionavam com o futuro dos trabalhadores. (E74)

Em relação a qualquer alteração no regulamento não me apercebi, nem fui informada, [...]. (E101)

Todas. Afinal o hospital funciona com os funcionários! (E74)

Nove enfermeiros que consideraram a informação suficiente apresentaram, também, justificativa. Os excertos permitem conhecer essas opiniões:

Foi suficiente, porque a informação foi sendo gradual; as mudanças, no meu ponto de vista, foram observadas posteriormente e de forma gradual. (E4) 
Dentro do serviço, a informação foi suficiente. Fornecida essencialmente pelo meu superior hierárquico. (E27)

A informação foi suficiente, embora não tenha sido discutida e falada em equipa. [...]. (E45)

As informações foram sendo obtidas, quando eram feitas questões. (E103)

Foram as suficientes para a situação. (E78)

\section{Classificação das relações dos enfermeiros}

Vários estudos referem que as relações entre os empregados e os seus supervisores ou líderes podem influenciar o desenvolvimento de empenhamento organizacional. Como exemplo, o fato do empenhamento afetivo ser mais forte entre os empregados cujos supervisores os tratam com consideração e com justiça ${ }^{14}$ e da relação com as chefias ser uma das variáveis preditoras do empenhamento organizacional ${ }^{15}$. Do mesmo modo, um estudo revela que quando existe relação mais favorável com a chefia, os enfermeiros se empenham mais na organização, quer do ponto de vista afetivo quer normativo, e têm ainda maior consciência dos custos de deixar a organização ${ }^{3}$. Efetivamente, os comportamentos dos colaboradores são influenciados pelas crenças sobre o quanto a organização valoriza a sua colaboração, pelo que é importante desenvolver uma cultura do local de trabalho e um sentido positivo da organização ${ }^{16}$.

Embora seja expressiva a percentagem de enfermeiros que considera a sua relação afetiva com o hospital quer antes das mudanças quer atualmente como média, não se pode deixar de referenciar que $33(20,9 \%)$, antes das mudanças, consideravam essa relação como elevada e, atualmente, apenas $13(8,2 \%)$ a consideram como tal, conforme expõe a Tabela 2 .

Quanto ao sentido de obrigação moral de permanecer nesse hospital, a maior percentagem considera-o quer antes das mudanças quer atualmente, atingindo a média (60,1\%). Contudo, 35(22,2\%), antes das mudanças, consideravam esse sentido elevado e, atualmente, esse grupo foi reduzido para 26(16,5\%), de acordo com a Tabela 2 .
No caso de o respondente considerar que a sua relação de obrigação para com o hospital é, atualmente, diferente do que era antes, foi pedido que referisse a que se deve essa mudança. Foram obtidas 18 respostas, cujos conteúdos se focalizam em reconhecimento, justiça e valorização das pessoas, como ilustram os seguintes excertos:

Perdeu-se o espírito de inter-ajuda, cada um está no seu local de trabalho e está distante dos outros funcionários [...]. (E91)

Pela desconsideração com que as pessoas são tratadas. (E13)

Há insatisfação, [...] pela falta de reconhecimento pelo meu desempenho. (E35)

[...] atualmente não sinto qualquer obrigação, pois a sensação é que somos dispensáveis e facilmente substituídos. Não existe uma valorização mínima pelo investimento que se faz [...]. (E52)

Porque há muito mais pessoal, e as pessoas não se conhecem também. (E66)

Talvez a falta de interesse de quem manda em que o hospital cative as pessoas. [...]. (E74)

Desmotivação pessoal, pelo não reconhecimento do trabalho empreendido. (E116)

Descaracterização da entidade, afastamento e despersonalização. (E123)

Neste momento, continuo a sentir obrigação moral de cumprir bem as minhas funções e promover a imagem da instituição a que pertenço. Afectivamente, as coisas alteraram-se um pouco, as relações entre os membros da equipa mudaram, para pior, talvez pela pressão $e$ excesso de trabalho que as mudanças e reestruturação trouxeram. (E91)

Sentimento de: injustiça; igualdade de classe; estrutura hierárquica mais rígida; menor autonomia. (E134)

Proporcionar carreiras dentro da empresa, onde haja progressão, objectivos, [...]. (E116)

TABELA 2: Classificação das relações dos enfermeiros com a organização. Portugal, 2011. (N=158)

\begin{tabular}{|c|c|c|c|c|c|c|c|c|}
\hline \multirow{2}{*}{ Classificação das relações } & \multicolumn{2}{|c|}{ Elevada } & \multicolumn{2}{|c|}{ Média } & \multicolumn{2}{|c|}{ Baixa } & \multicolumn{2}{|c|}{ NR } \\
\hline & $f$ & $\%$ & f & $\%$ & f & $\%$ & $f$ & $\%$ \\
\hline $\begin{array}{l}\text { Relação afetiva com este hospital antes } \\
\text { das 'mudanças' }\end{array}$ & 33 & 20,9 & 100 & 63,3 & 8 & 5,1 & 17 & 10,8 \\
\hline $\begin{array}{l}\text { Relação afetiva com este hospital } \\
\text { atualmente }\end{array}$ & 13 & 8,2 & 114 & 72,2 & 17 & 10,8 & 14 & 8,9 \\
\hline $\begin{array}{l}\text { Sentido de obrigação moral de perma- } \\
\text { necer neste hospital antes 'mudanças' }\end{array}$ & 35 & 22,2 & 95 & 60,1 & 11 & 7,0 & 17 & 10,8 \\
\hline $\begin{array}{l}\text { Sentido de obrigação moral de } \\
\text { permanecer neste hospital atualmente }\end{array}$ & 26 & 16,5 & 95 & 60,1 & 20 & 12,7 & 17 & 10,8 \\
\hline
\end{tabular}


A minha relação mantém-se fruto do gosto que faço na profissão que tenho e na qualidade dos recursos para o meu desempenho [...]. (E90)

A maioria dos enfermeiros (70,9\%) registrou que, atualmente, a relação entre a administração e os funcionários é a mesma que antes; contudo, 15,8\% a consideram pior que antes.

Para as questões: $\mathrm{O}$ que é que mudou? e $\mathrm{O}$ que acha que podia ser feito para melhorar?, as respostas vão no sentido do distanciamento/aproximação. A fim de ilustração, apresentam-se alguns excertos:

A administração [...] distanciou-se da realidade dos serviços; [...]. (E35)

Maior prepotência; menos proximidade; menor acessibilidade. (E90)

Parece-me que a administração desconhece um pouco a realidade vivida nos serviços e as dificuldades por que nós funcionários passamos para exercermos as nossas funções da melhor forma. (E105)

Mudar as pessoas que mandam. Falta-lhes mais sensibilidade e menos autoritarismo. (E138)

A relação da administração com os funcionários é distante. (E66)

[...] A única forma de mudar é através de uma maior relação entre os referidos, mas tem de haver vontade de ambas as partes. (E74)

Mudar as políticas institucionais. (E20)

Mais reconhecimento pelo esforço e zelo evidenciado no meu desempenho. (E116)

\section{Comparação de valores: empenhamento organizacional}

No estudo de $2002^{13}$, a amostra foi constituída por 161 enfermeiros, sendo $126(78,3 \%)$ do sexo feminino. Os grupos etários mais expressivos foram até aos 30 anos 60(37,3\%), e dos 30-39 anos 61(37,9\%). A categoria profissional mais representada foi de enfermeiro graduado $72(44,7 \%)$. Seguiram-se as categorias de enfermeiro nível I 64 (39,7\%) e de enfermeiro especialista 25(15,5\%). Ainda, $105(65,1 \%)$ enfermeiros, que responderam ao questionário, trabalhavam na organização há menos de 10 anos.

O empenhamento afetivo e o empenhamento normativo ${ }^{13,15,16}$ apresentam, em 2011, comparativamente a 2002, valores médios inferiores. Por sua vez, o empenhamento instrumental ${ }^{13,15,16}$ revela, na mesma comparação, valores médios superiores. As diferenças de médias são estatisticamente significativas, conforme dispõe a Tabela 3.

De fato, 33(20,9\%) enfermeiros, antes das mudanças, consideravam a relação afetiva com o hospital como elevada e, atualmente, apenas $13(8,2 \%)$ a consideram como tal. Também o sentido de obrigação moral de permanecer no hospital, antes das mudanças, significava elevada por $35(22,2 \%)$. Atualmente, esse grupo foi reduzido para 26(16,5\%), segundo a Tabela 2 .

Tratando-se de um indicador com menos efeitos positivos para o desempenho organizacional. Esperava-se que o empenhamento instrumental apresentasse um baixo valor médio, mas não é o que se verifica. Este valor ultrapassa até o do empenhamento normativo. E, comparando $2002^{13}$ com 2011, verifica-se um aumento. Tem-se, assim, um indicativo de que a manutenção da ligação à organização é cada vez mais devida aos custos (p. ex. falta de alternativas) em que o colaborador incorreria por sair da instituição.

No espaço destinado a observações, foram deixadas referências à esperança de que as conclusões sejam divulgadas, conforme se ilustra:

Espero que este questionário tenha algum impacto e ajude a ultrapassar algumas dificuldades sentidas nos serviços. (E20)

Tem que valorizar as pessoas que trabalham nesta instituição. [...]. (E138)

Desejo que seja feita uma tomada de consciência por parte da administração deste hospital, sobre o que realmente se passa no dia a dia dos funcionários deste hospital; [...]. (E35)

TABELA 3: Comparação de valores do empenhamento organizacional em 2002 e 2011. Portugal, 2011. $(\mathrm{N}=158)$

\begin{tabular}{|c|c|c|c|c|}
\hline Variáveis & $\begin{array}{c}2002 \\
\left(\mathrm{n}=\frac{161)}{\bar{x}}\right. \\
\mathrm{sd}\end{array}$ & $\begin{array}{c}2011 \\
\left(\mathrm{n}=\frac{164)}{\bar{x}}\right. \\
\text { sd }\end{array}$ & $\mathrm{t}(\mathrm{gl})$ & $p$ \\
\hline Empenhamento afetivo & $\begin{array}{l}3.71 \\
.73\end{array}$ & $\begin{array}{c}3.40 \\
.92\end{array}$ & $3.241(284)$ & .001 \\
\hline Empenhamento normativo & $\begin{array}{c}2.80 \\
.78\end{array}$ & $\begin{array}{c}2.60 \\
.90\end{array}$ & $2.051(308)$ & .041 \\
\hline Empenhamento instrumental & $\begin{array}{c}2.82 \\
.77\end{array}$ & $\begin{array}{c}3,01 \\
.41\end{array}$ & $-2.699(307)$ & .007 \\
\hline
\end{tabular}




\section{CONCLUSÃO}

As mudanças que se sucedem nas organizações remetem para a maior necessidade de se avaliar e para a relevância de se compreender o comportamento dos colaboradores, as suas opiniões e, particularmente, o seu empenhamento organizacional.

As informações fornecidas sobre as mudanças no hospital e sobre o modo como essas mudanças poderiam afetar foram consideradas insuficientes por parte considerável-78(47,5\%) - dos participantes. Estes justificaram suas respostas alegando que houve ausência de informação, que necessitariam de entender a mudança e de serem integrados como elementos participativos no processo, além de reforço contínuo da motivação para a mudança.

É notória a diminuição das relações afetivas e normativas dos enfermeiros com a organização, nos dois momentos estudados, sendo a diferença de médias, no que respeita ao empenhamento afetivo, estatisticamente significativa.

São contributos deste estudo a avaliação do impacto do processo de reestruturação nos níveis de empenhamento organizacional dos enfermeiros; a verificação de que existem diferenças nos níveis de empenhamento antes e após o processo de reestruturação. Embora com a cautela necessária a qualquer generalização, os resultados deste estudo podem ser projetados a outras instituições de saúde cujas reformas passem igualmente por processos de reestruturação.

Como recomendações, no sentido de reforçar o empenhamento organizacional e partindo da sugestão deixada por certos participantes, é necessário que a administração e os gestores tomem a proximidade e a informação aos colaboradores como elemento determinante para a identificação com a organização pelo fato de o empenhamento favorecer, entre outros, comportamentos positivos e de bem-estar, de motivação e de produtividade.

Este estudo não é isento de limitações que, apesar de não comprometerem os resultados, devem ser referidas. Assim, deve-se apontar a baixa taxa de resposta, o fato de apenas terem sido inquiridos enfermeiros e a não inclusão da opinião dos gestores da organização. É preciso acrescentar que, apesar de serem excluídos os respondentes que não trabalhavam na instituição antes da reestruturação, não se tratou de um estudo emparelhado o que seria o ideal em termos comparativos.

\section{REFERÊNCIAS}

1.Aas I. Incentives and financing methods. Health Policy.1995; 34.205-20.

2.Camelo SH. Políticas de recursos humanos: sistema único de saúde, bases legais e implicações para a enfermagem. Rev enferm UERJ. 2009; 17:589-94.

3.Ferreira M, Silva I. Empenhamento organizacional de enfermeiros e relação com a chefia. Rev enferm UERJ. 2013; 21:156-61.

4.Iverson R, Roy P. A causal model of behavioural commitment: evidence from a study of Australian blue-collae employees. Journal of Management. 1994; 20:15-41.

5.Hunt S, Morgan R. Organizational commitment: one of many commitments or key mediating construct? Academy of Management Journal.1994; 37:1568-87.

6.McCaul H, Hinsz, V, McCaul D. Assessing organizational commitment: an employee's attitude toward the organization. The Journal of Applied Behavioural Science. 1995; 31:80-90.

7.Vieira TP, Renovato RD, Sales CB. Compreensões de liderança pela equipe de enfermagem. Cogitare Enferm.2013; 18:253-60.

8.Davies C. Competence versus care? Gender and caring work revisited. Acta Sociologica.1995; 38:17-31.

9. Walby S, Greenwell J, Mackay L, Soothill K. Medicine and nursing: professions in a changing health service. London (UK): Sage Publications; 1994.

10.Daykin N, Clark B. They'll still get the bodily care. Discourses of care and relationships between nurses and health care assistants in the NHS. Sociology of Health \& Illness. 2000; 22:349-63.

11.Meyer J, Allen N. A three-component conceptualization of organizational commitment. Human Resourec Management Review. 1991; 1:61-89.

12.Meyer J, Allen N. Commitment in the workplace. London (UK): SAGE Publications; 1997.

13.Ferreira MM. Empenhamento organizacional de profissionais de saúde em hospital com diferentes modelos de gestão [tese de doutoramento]. Braga $(\mathrm{Pt})$ : Universidade do Minho; 2005.

14.DeCotiis T, Summers T. A path analysis of a model of the antecedents and consequences of organizational commitment. Human Relations. 1987; 40:445-70.

15.Frederico MM. Empenhamento organizacional de enfermeiros em hospitais com diferentes modelos de gestão: papel de variáveis de contexto. Referência. 2005; 1:53-62. 16.Frederico-Ferreira M. Percepção de suporte organizacional em hospitais públicos: estudo em enfermeiros. Análise Psicológica. 2008; 4:697-706. 